Open Access : ISSN : 1848-7718

Original scientific paper

http://www.pub.iapchem.org/ojs/index.php/admet/index

\title{
Mucoadhesive Polymer Hyaluronan as Biodegradable Cationic/Zwitterionic-Drug Delivery Vehicle
}

\author{
Francisco Torrens $\underline{\Xi}$ and Gloria Castellano ${ }^{1}$ \\ Institut Universitari de Ciència Molecular, Universitat de València, Edifici d'Instituts de Paterna, P. O. Box 22085, \\ E-46071 València, Spain \\ ${ }^{1}$ Facultad de Veterinaria y Ciencias Experimentales, Universidad Católica de Valencia San Vicente Mártir, Guillem de \\ Castro 94, E-46001 València, Spain
}

${ }^{\square}$ Corresponding Author: E-mail: torrens@uv.es; Tel.: +34-963-544-431; Fax: +34-963-543-274

Received: July 23, 2014; Revised: August 28, 2014; Published: January 09, 2015

\begin{abstract}
Mucoadhesive polymers in pharmaceutical formulations release drugs in mucosal areas. They interact and fix to mucus through molecular interpenetration, etc., which increase drug bioavailability. Polymers physicochemical properties affect formulation mucoadhesion, rheological behaviour and drug absorption. Hyaluronan (HA) is selected as a mucoadhesive and biodegradable polymer. Geometric, topological and fractal analyses are carried out with program TOPO. Reference calculations are performed with algorithm GEPOL. Procedure TOPO underestimates molecular volume by $0.7 \%$. The error results $5 \%$ in surface area and derived topological indices. The solvent-accessible surface is undercalculated by $3 \%$ : from hexamer HA to HA.3Ca and hydrate, the hydrophobic term rises by $42 \%$ and decays by $26 \%$, as well as the hydrophilic part drops by $14 \%$ and rises by $58 \%$, in agreement with the number of $\mathrm{H}$-bonds. The accessibility rises by $9 \%$ and decays by $8 \%$. The fractal dimension is underevaluated by $1 \%$ and, for $H A$, it results 1.566; on going to $\mathrm{HA} \cdot 3 \mathrm{Ca}$ and hydrate, it rises by $2 \%$ and $1 \%$. The nonburied-atoms dimension increases by $11 \%$ : for $\mathrm{HA}$, it results 1.725. When going to $\mathrm{HA} \cdot 3 \mathrm{Ca}$ and hydrate, it augments by $4 \%$ and $0.3 \%$. Ongoing from HA to HA.3Ca and hydrate, the external minus molecular dimension enlarges by $20 \%$ and decays by $9 \%$. The hydrate globularity is lower than for water, $\mathrm{Ca}^{2+}$ and averages of O-atoms in HA. The rugosity of $\mathrm{Ca}^{2+}$ is smaller than for hydrate, averages of $\mathrm{O}$-atoms in $\mathrm{HA}$ and water. The accessibilities of $\mathrm{Ca}^{2+}$ and water are greater than for hydrate. As cations exchange in $\mathrm{HA} \cdot 3 \mathrm{Ca}$ requires $\mathrm{Ca}^{2+}$ alteration, rises of drug zwitterionic character and acidic $\mathrm{pH}$ increase absorption.
\end{abstract}

\section{Keywords}

medicine absorption; medicine delivery; dipole moment; fractal dimension; metal hyaluronate; mucosa.

\section{Introduction}

Hyaluronic acid (HA) is a high-molecular-weight (MW) (HMW) polysaccharide present in the extracellular matrix of most vertebrate tissues [1]. Its functions vary from maintaining constant volume of interstitial fluid to organizing extracellular matrix and immunosuppression [2]. Its presence on plasma membranes and concentration variation in pericellular spaces are associated with cell aggregation during morphogenesis and metastasis formation during malignant transformation and tumours invasion [3-5]. It is an anionic, nonsulphated, linear, HMW polyglycosaminoglycan (cf. Figure 1) consisting of repeating units 
of disaccharide D-glucuronic acid (GCU)- $\beta(1 \rightarrow 3)-N$-acetyl-D-glucosamine (NAG)- $\beta(1 \rightarrow 4)$. An HA molecule consists of $10^{4} \mathrm{GCU} / \mathrm{NAG}$. Its anionic charge under physiological conditions is caused by GCU $\mathrm{COO}^{-}$, which $\mathrm{M}^{2+}$ interaction contributes to global supramolecular structure [6]. Other factors include: $\mathrm{pH}$, temperature, hydration and, especially, $\mathrm{M}^{2+}[7,8]$. Structural and literature data for transition metal complexes with $\mathrm{HA}$ are limited to aqueous co-ordination complexes with $\mathrm{Ca}^{2+}, \mathrm{Ag}^{+}, \mathrm{Cd}^{2+}, \mathrm{Pb}^{2+}$ and $\mathrm{Fe}^{3+}$ [9-11]. X-ray fibre diffraction solved solid-state structure of $\mathrm{M}^{2+} \mathrm{HA}$ where the formation of 2- and 4-fold-helices was reported [12-15]. Polyanion conformation is stabilized by $H$-bonds across glycosidic linkages between HA monomers. Adjacent antiparallel chains are held together through $-\mathrm{COO}^{-}-\mathrm{Ca}^{2+}-{ }^{-} \mathrm{OOC}-$ bridges and six $\mathrm{H}$ bonded water molecules. The polymer secondary structure is similar to $\mathrm{Ca}^{2+} \mathrm{HA}$ for other $\mathrm{M}^{2+}$. Amorphous $\mathrm{M}^{2+} \mathrm{HA}(\mathrm{M}=\mathrm{Cu}, \mathrm{Ni}, \mathrm{Mn}, \mathrm{Co})$ was prepared at $\mathrm{pH} 5.5$ precipitating aqueous solutions with cold ethanol. Local structure around $\mathrm{M}^{2+}$ was determined by extended X-ray absorption fine structure (EXAFS) and X-ray absorption near edge structure (XANES) $[16,17]$. Co-ordination polyhedron around $\mathrm{Cu}^{2+}$ is a distorted octahedron: four O-atoms at a distance of $1.95 \AA$ occupy planar equatorial sites; at axial places $\mathrm{O}$-atoms are present at $2.46 \AA$. Though $\mathrm{O}$-atoms are preferred at axial locations, $\mathrm{N}$-atoms from NAG cannot be excluded.

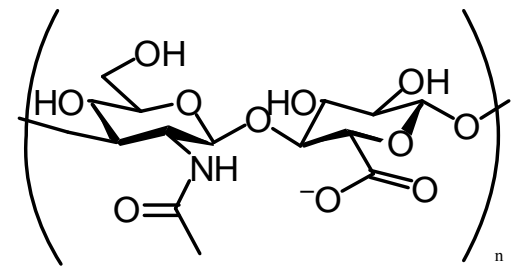

Figure 1. Disaccharide repeating unit of HA comprising GCU/NAG. The MW ranges in $10^{4}-10^{7} \mathrm{~g} \cdot \mathrm{mol}^{-1}$.

By using quantum chemical methods, the basic GCU/NAG unit was studied. Semi-empirical and $a b$ initio molecular orbital $(\mathrm{MO})$ calculations showed optimized geometries in agreement with crystallographic data [18]. The $\mathrm{Ca} / \mathrm{Cu}^{2+} \mathrm{HA}$ are amorphous materials. A combined quantum mechanical/molecular mechanics (QM/MM) approach [19] to enzymology and $\mathrm{M}^{2+}$-protein/HA binding allowed structural elucidation [2028]. Transition- $\mathrm{M}^{2+}$ binding was studied by using density-functional theory (DFT) [29-33]. An $\mathrm{HA}: \mathrm{Ca} / \mathrm{Cu}^{2+}$ complexation QM/MM was performed [34]. The HA plays a structural role in cartilage and other tissues. Aggrecan, the cartilage proteoglycan, is bound to HA chains, the bond being stabilized by link proteins [35]. The formed aggregates of $\mathrm{MW} \sim 10^{8} \mathrm{~g} \cdot \mathrm{mol}^{-1}$ are deposited within the collagen framework, without which interaction the proteoglycans would not be retained in cartilage. Mucoadhesive polymers were used in pharmaceutical formulations to release drugs in mucosas [gastrointestinal (GI)/vaginal tracts, ocular mucosa, bucal/nasal cavity] [36]. They fix to mucus through mechanisms (molecular interpenetration, van der Waals forces, hydrophobic interactions, electrostatic forces, $\mathrm{H}$-bonds) increasing drug bioavailability [37-40].

In earlier publications, program TOPO was applied to the valence topological charge-transfer indices for the molecular dipole moment $[41,42]$, as well as fractal dimension of percutaneous absorption enhancer phenyl alcohols [43] and 4-alkylanilines [44]. Lysozyme showed hydrolytic activity vs. peptidoglycans [4548]. A new tool was described for interrogating macromolecular structure [49]. In the present report, HA geometric, topological and fractal analyses are performed with TOPO. The aim of this study is to find properties distinguishing $\mathrm{HA} \cdot 3 \mathrm{Ca} \cdot 9 \mathrm{H}_{2} \mathrm{O}$. The goal is to validate the indices by using $\mathrm{HA}$ differentiation. The ultimate reason for modelling is to improve pharmaceutical formulations to release drugs in mucosal areas as HA properties affect mucoadhesion, rheological behaviour and drug absorption with the goal of increasing biodisponibility and decreasing toxicity. The following section describes the experimental in 
silico computational methods. Next, two sections illustrate and discuss the results. Finally, the last section summarizes our conclusions.

\section{Experimental}

In our program TOPO for the theoretical simulation of crystal-fragment shape [50], structure surface is represented by the external surface of a set of overlapping spheres with appropriate radii, centred on the atomic nuclei [51,52]. A crystal fragment is treated as a solid in space defined by tracing spheres about atomic nuclei. It is computationally enclosed in a graduated rectangular box, and the geometric descriptors are evaluated by counting the points within the solid or close to chosen surfaces. The crystal-fragment volume is approximated as $V=P \cdot G I^{3}$, where $P$ is the number of points within the fragment volume (within a distance $R_{X}$ of any atomic nucleus $X$ ) and GRID is the mesh-grid size. As a first approximation, the crystal-fragment bare surface area was calculated as $S=Q \cdot G^{\prime} I^{2}$, where $Q$ is the number of points close to the bare surface area (within a distance between $R_{X}$ and $R_{X}+$ GRID of any atomic nucleus $X$ ). However, the estimate was improved: if a point falls exactly on the surface of one of the atomic spheres it accounts indeed for $\mathrm{GRID}^{2}$ units of area on fragment bare surface, which is because total surface of atom $X$ can accommodate $4 \pi R_{x}{ }^{2} / G$ RID $^{2}$ points. When a point falls beyond the surface it represents GRID $^{2}$ units of area on the surface of a sphere of radius $R>R_{X}$, not on the surface of atom $X$ on which it accounts only for a fraction of this quantity: $\operatorname{GRID}^{2}\left(R_{x} / R\right)^{2}$. The total bare surface area is calculated as $S=F \cdot G R D^{2}$, where $F$ is the sum of elements $\mathrm{AF}=R_{X}{ }^{2} / R^{2}(I)$ for those points close enough to the surface of any atom $X$. The $R_{X}{ }^{2}$ is the square radius of atom $X$ and $R^{2}(I)$ is the square distance of point $I$ from atomic nucleus $X$. Two topological indices of crystal-fragment shape are calculated: $G=S_{e} / S\left(S_{e}=\right.$ surface of an equivalent sphere) stands for the fragment globularity and $G^{\prime}=S / V$ denotes the fragment rugosity.

The hydrated-system properties are related to the contact surface between solute and water molecules. Another crystal-fragment geometric descriptor was proposed: the solvent-accessible surface area AS [53], which is defined by using a probe sphere that is allowed to roll on the outside while maintaining contact with the bare surface [54]. It is calculated in the same way as the bare surface area by using pseudo-atoms whose van der Waals radii [55] were increased by the probe radius $R$ [56]. The accessibility is a dimensionless quantity ranged in 0-1 representing the ratio of solvent-accessible surface area in a particular structure to solvent-accessible surface area of the same atom when isolated from the crystal-fragment. The fractal dimension, $D$, results [57]:

$$
D=2-\frac{d(\log \mathrm{AS})}{d(\log R)}
$$

It provides a quantitative indication of the degree of surface accessibility towards different solvents [58]. Program TOPO allows an atom-to-atom analysis of $D$ on every atom $i$ to obtain an atomic dimension index $D_{i}$ from the atomic contributions to $\mathrm{AS}_{i}$. The $D_{i}$ is weight averaged to obtain a new crystal-fragment dimension index $D^{\prime}=\left(\Sigma_{i} A S_{i} D_{i}\right) / A S$, where $A S_{i}$ are used as weights for $D_{i}$. If an $\mathrm{AS}_{i}=0$ for any probe, $D_{i}$ cannot be calculated for atom $i$ and this does not contribute to $D^{\prime}$, which represents a $D$ averaged for atoms nonburied to any solvent-accessible surface in the range of probe spheres. A version of TOPO was implemented in algorithms AMYR [59], GEPOL [60] and SURMO2 [61]. Procedure AMYR performs the theoretical simulation of molecular associations and chemical reactions. Software GEPOL performs a 
triangular tessellation of the crystal-fragment surface. It is used for reference calculations. Codes TOPO and GEPOL recognize the cavity-like spaces in crystal-fragments and are adequate to study intercalation compounds; however, SURMO2 does not distinguish internal cavities. Combination SURMO2 with TOPO or GEPOL allows characterizing the crystal-fragment surface of the cavities. Our version of SURMO2 was corrected for deviation from the spherical shape, by dividing the contribution of every point by the cosine of the angle formed by the semi-axis and the corresponding normal vector to the surface at this point. The volume and surface areas of the crystal fragments with cavities were corrected by maximizing in every angular orientation the distance of the most distant atom in each semi-axis.

\section{Calculation Results}

Doubly crosslinked networks (DXNs) were engineered by embedding gelatine conjugated HA hydrogel particles (HGPs) (gHGPs) in a secondary net established by HA glycidyl methacrylate (GMA) (HAGMA) (cf. Figure 2) [62].

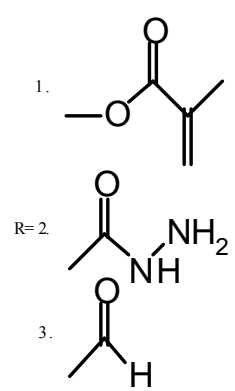

Figure 2. Chemical modifications in synthetic procedures for the fabrication of HA HGPs and DXNs.

For drug administration on mucous membranes and tissues, as well as skin, the active principle is prepared in matrix systems with a hydrophilic polymer \{Carbopol ${ }^{\circ}$ [poly(acrylic acid) (PAA), cf. Figure 3a], $\mathrm{HA}$ \} and alcohol [propylene glycol (PG, Figure 3b), poly(ethylene glycol) (PEG, Figure 3c)].

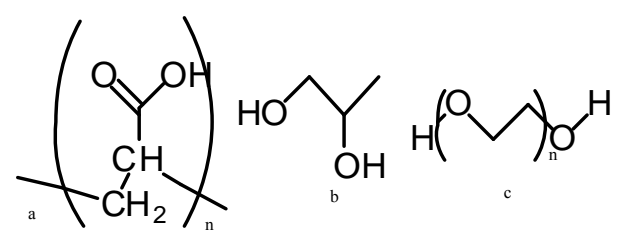

Figure 3. (a) Poly(acrylic acid) (PAA); (b) propylene glycol (PG); (c) poly(ethylene glycol) (PEG).

Fourier-transform infrared (FTIR) spectroscopy showed that the carboxylic acid groups $\mathrm{COOH}$ of PAA react completely with the alcohol groups $\mathrm{OH}$ in the matrix [63]:

$$
\sim \mathrm{O}-\mathrm{H}+\mathrm{H}-\mathrm{O}-\mathrm{C}(=\mathrm{O}) \sim \sim \sim \mathrm{O}-\mathrm{C}(=\mathrm{O}) \sim+\mathrm{H}_{2} \mathrm{O}
$$

In gel $\mathrm{Ca}$ alginate used for wound dressing, $\mathrm{Ca}^{2+}$ releasing helps in healing and exchanges exuded $\mathrm{Na}^{+}$. Stable cationic colloids were elaborated by using chitosan (CS):HA polyelectrolyte complexation [64]. $\mathrm{Ag}^{+} / \mathrm{Ag}_{3} \mathrm{PO}_{4}$ nanoparticles: $\mathrm{HA} / \mathrm{CS}$ complexes (cf. Figure 4 ) resulted antimicrobial $[65,66]$. Hydrogels are used in medical applications, e.g., implants, tissue engineering and contact lenses. 


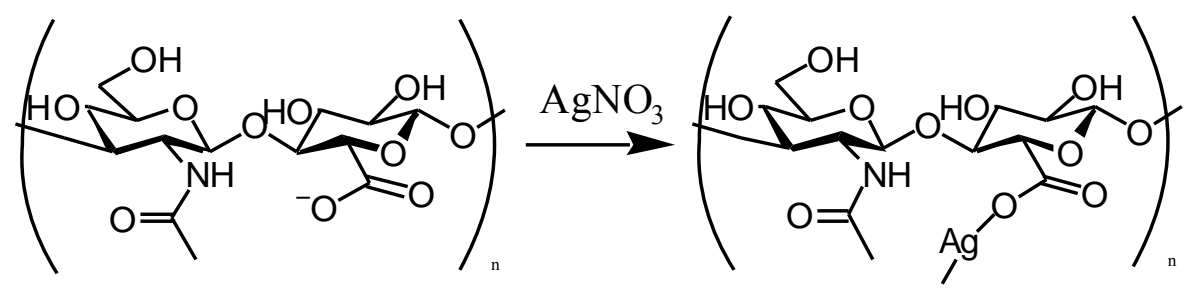

Figure 4. Suggested structure of complex of hyaluronic acid (HA) and silver $\mathrm{Ag}^{+}$.

The HA was selected as a mucoadhesive and biodegradable polymer. Polar molecules (cf. Table 1) administered with HA show high dipole moment. Notice the low MW of metronidazole, etc. and the low human skin permeability of caffeine used as transdermal anticellulite. Some small, lipid-soluble drugs cross the blood-brain barrier (BBB) simply by diffusion through the cell membrane and others, e.g., caffeine, enter successfully through specialized transporter proteins.

A model showed that the decimal logarithm of 1-octanol-water partition coefficient $(\log P)$ positively correlated and MW negatively associated with $\log K_{\mathrm{p}}[67]$ :

$$
\log K_{p}=-6.3+0.71 \log P-0.0061 \mathrm{MW}, \quad n=93 \quad r=0.82
$$

where $n$ is the number of points and $r$, correlation coefficient. Table 2 shows the administration routes of drug metronidazole for bacterial, fungal and protozoal vaginitis $[68,69]$.

Table 1. Molecular dipole moments of water, theophylline and polar molecules administered with $\mathrm{HA}$.

\begin{tabular}{|c|c|c|c|c|c|c|c|}
\hline Molecule & $\mu(D)^{\mathrm{a}}$ & Ref. $^{b}$ & $\mathrm{MW}^{\mathrm{c}}$ & $\mathrm{p} K_{\mathrm{a}}^{\mathrm{d}}$ & $\log P^{\mathrm{e}}$ & $\log K_{\mathrm{p}}^{f}$ & Uses \\
\hline Water & 1.861 & 1.85 & 18 & 15.74 & -1.38 & -6.71 & Solvent and metabolism \\
\hline Eugenol & 2.378 & - & 164 & 10.19 & 2.27 & - & Local antiseptic and anaesthetic \\
\hline Theophylline & 3.262 & - & 180 & 8.81 & -0.773 & - & Respiratory diseases \\
\hline Caffeine & 3.567 & 3.64 & 194 & 10.4 & -0.07 & -7.14 & Cellulite \\
\hline Metronidazole & 3.681 & - & 171 & 2.62 & -0.02 & - & Bacterial/fungal/protozoal vaginitis \\
\hline Terconazole & 4.098 & - & 532 & $<1.5$ & 3.51 & - & Antifungal \\
\hline Minoxidil & 4.292 & - & 209 & 4.61 & 1.24 & - & Androgenic alopecia \\
\hline Betamethasone & 5.346 & - & 392 & 12.42 & 1.94 & - & Anti-inflammatory and immunosupressor \\
\hline
\end{tabular}

Table 2. Administration routes of drug metronidazole for bacterial, fungal and protozoal vaginitis.

\begin{tabular}{cccc}
\hline Route & Onset & Peak (hr) & Duration (hr) \\
\hline Oral (PO) & Rapid & $1-3$ & 8 \\
PO (extended) & Rapid & Unknown & Up to 24 \\
Intravenous (IV) & Rapid & End of infusion & $6-8$ \\
Topical & Unknown & $6-12$ & Unknown \\
Vaginal & Unknown & $6-12$ & 12 \\
\hline
\end{tabular}

An HA comparative analysis was performed in three forms: hexamer (trimer of heterodimers) HA (cf. Figure 5), $\mathrm{HA} \cdot 3 \mathrm{Ca}$ and $\mathrm{HA} \cdot 3 \mathrm{Ca} \cdot 9 \mathrm{H}_{2} \mathrm{O}$. The geometry of the systems was taken from the Protein Data Bank code 4 HYA (X-ray fibre diffraction). 


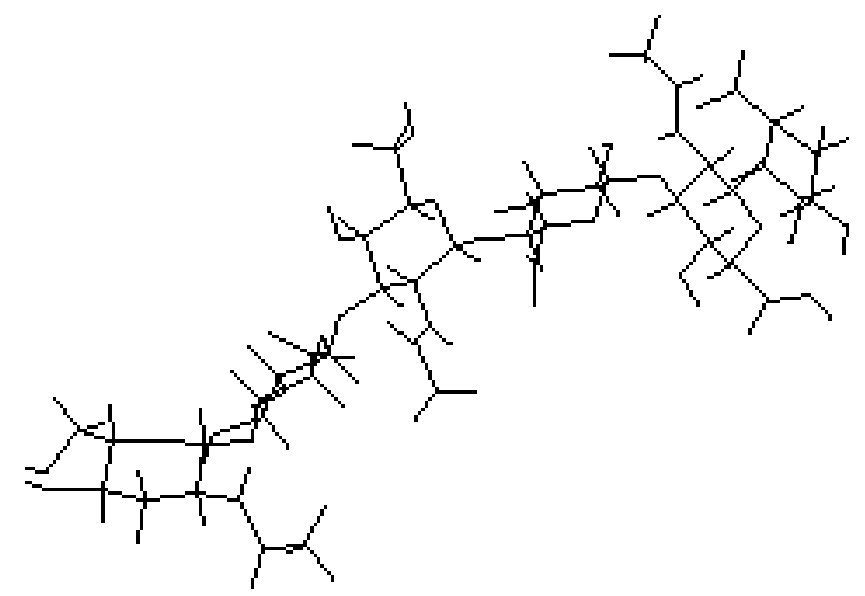

Figure 5. Wire-frame molecular structure of HA (perspective view).

In 4HYA, nine crystallization water molecules are included most strongly bound in the first hydration shell (cf. Figure 6).

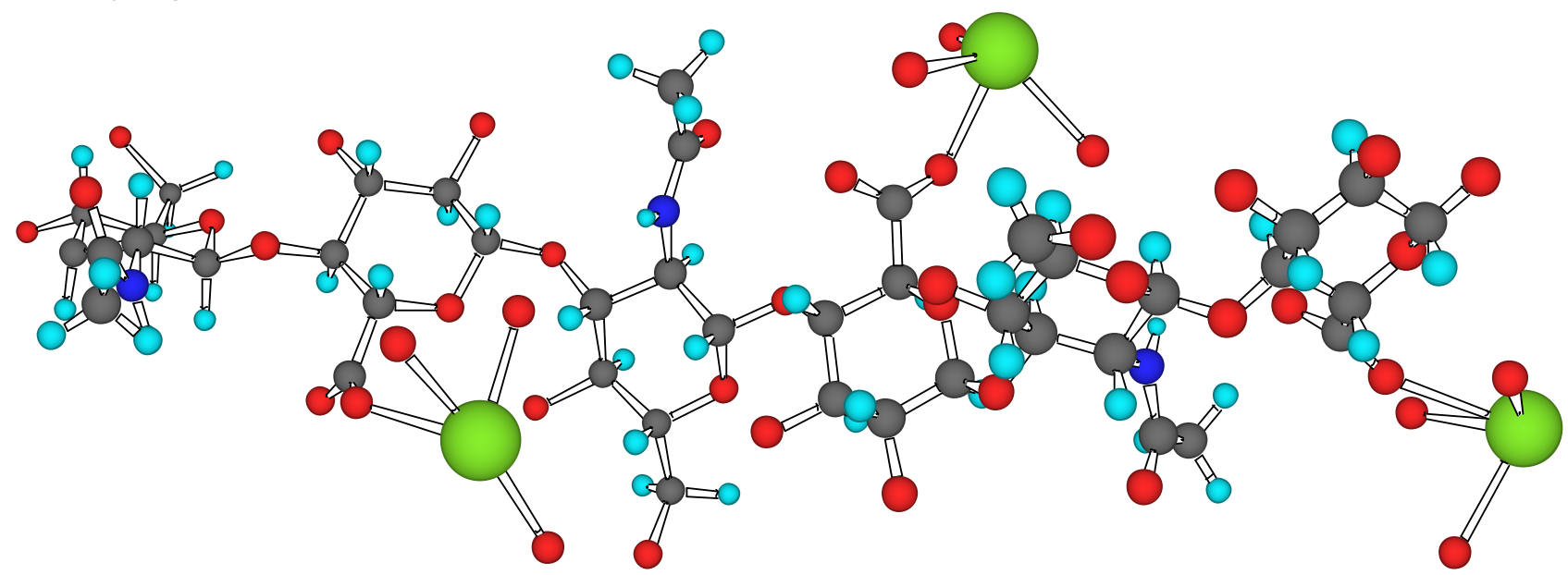

Figure 6. Hydrogen-suppressed ball-and-stick structure of hyaluronic acid hexamer $\mathrm{HA} \cdot 3 \mathrm{Ca} \cdot 9 \mathrm{H}_{2} \mathrm{O}$.

The 4HYA consists of six saccharide residues (126 atoms, cf. Table 3 ) with $\mathrm{MW}=1123 \mathrm{~g} \cdot \mathrm{mol}^{-1}$. The glycosaminoglycan hexamer co-ordinates three $\mathrm{Ca}^{2+}$ ions also surrounded by at least nine water molecules. The $11 \mathrm{~N} / \mathrm{O}-\mathrm{H} . . . \mathrm{O} \mathrm{H}$-bonds include one $\mathrm{N}-\mathrm{H} . . . \mathrm{O}$ and $10 \mathrm{O}-\mathrm{H} . . . \mathrm{O}$, e.g., three pairs of $\mathrm{H}$-shared $\mathrm{H}$-bonds. Many $\mathrm{H}$-bonds are formed because of the polyanionic nature of HA main chain.

Table 3. Number of atoms, hydrogen bonds and molecular weight of hyaluronic acid (HA).

\begin{tabular}{cccc}
\hline Molecule & No. of Atoms & MW $\left(\mathrm{g} \cdot \mathrm{mol}^{-1}\right)^{\mathrm{a}}$ & Number of N/O-H...O Hydrogen Bonds \\
\hline $\mathrm{HA}$ & 126 & 1123 & $1 \mathrm{~N}-\mathrm{H} \ldots \mathrm{O}$ \\
$\mathrm{HA} \cdot 3 \mathrm{Ca}$ & 129 & 1243 & $1 \mathrm{~N}-\mathrm{H} \ldots \mathrm{O}$ \\
$\mathrm{HA} \cdot 3 \mathrm{Ca} \cdot 9 \mathrm{H}_{2} \mathrm{O}$ & 152 & 1401 & $11(1 \mathrm{~N}-\mathrm{H} \ldots \mathrm{O}+10 \mathrm{O}-\mathrm{H} \ldots \mathrm{O}, 6$ shared $)$
\end{tabular}

Figure 7 illustrates four out of $11 \mathrm{~N} / \mathrm{O}-\mathrm{H} \ldots \mathrm{O} \mathrm{H}$-bonds in $\mathrm{HA} \cdot 3 \mathrm{Ca} \cdot 9 \mathrm{H}_{2} \mathrm{O}$ : one $\mathrm{N}-\mathrm{H}$...O and three out of 10 $\mathrm{O}-\mathrm{H}$...O. 


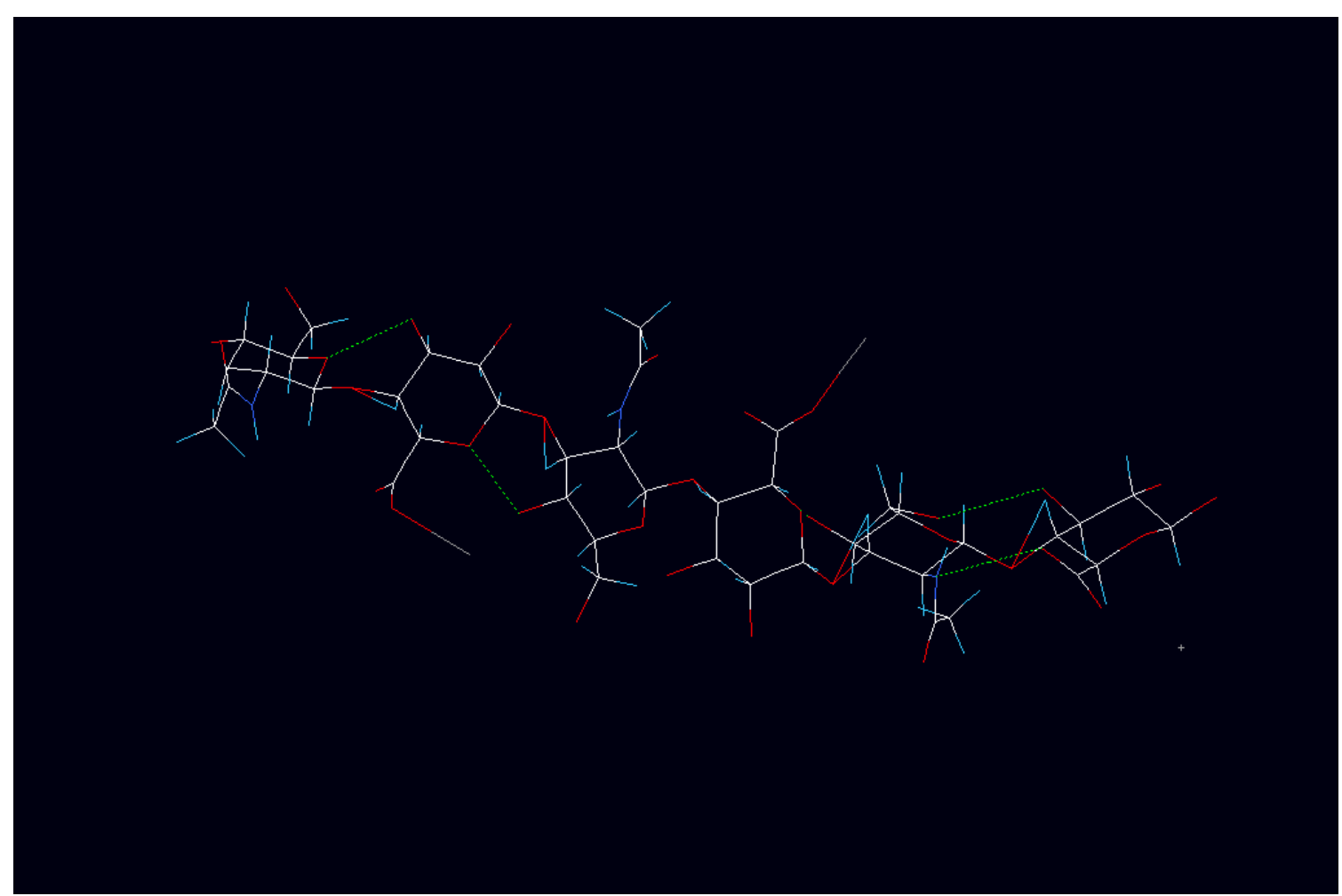

Figure 7. Four of the N/O-H...O hydrogen bonds of hyaluronic acid hexamer $\mathrm{HA} \cdot 3 \mathrm{Ca} \cdot 9 \mathrm{H}_{2} \mathrm{O}$.

Van der Waals molecular surface of $\mathrm{HA} \cdot 3 \mathrm{Ca} \cdot 9 \mathrm{H}_{2} \mathrm{O}(c f$. Figure 8$)$ shows some small open cavities.

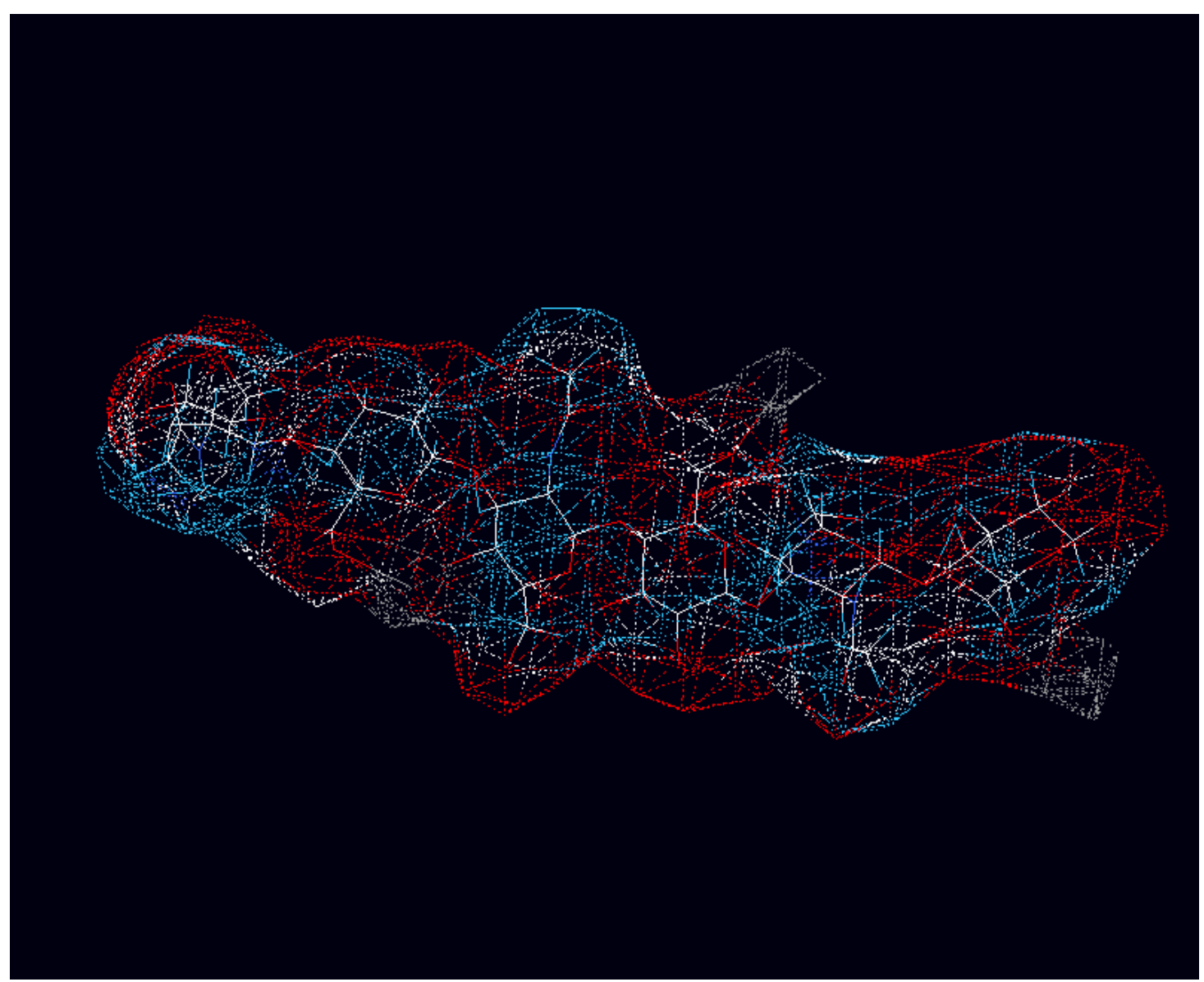

Figure 8. Van der Waals molecular surface of hyaluronic acid hexamer $\mathrm{HA} \cdot 3 \mathrm{Ca} \cdot 9 \mathrm{H}_{2} \mathrm{O}$. 
Geometric and topological analyses were performed with our program TOPO (cf. Table 4). Reference calculations were performed with our version of GEPOL. Algorithm TOPO underestimated the molecular volumes $V$ and surface areas $S$ by $0.7 \%$ and $5 \%$, respectively. Surface-derived molecular globularities $G$ were overestimated by $5 \%$ and rugosities $G^{\prime}$ resulted underestimated by $5 \%$.

Table 4. Geometric descriptors and topological indices of hyaluronic acid (HA).

\begin{tabular}{ccccccccc}
\hline Molecule & $V^{\mathrm{a}}$ & $V$ Ref. $^{\mathrm{b}}$ & $S^{\mathrm{c}}$ & $S$ Ref. $^{\mathrm{b}}$ & $G^{\mathrm{d}}$ & $G$ Ref. $^{\mathrm{b}}$ & $G^{\text {e }^{2}}$ & $G^{\prime}$ Ref. $^{\mathrm{b}}$ \\
\hline $\mathrm{HA}$ & 816.4 & 822.8 & 942.78 & 999.24 & 0.448 & 0.425 & 1.155 & 1.214 \\
$\mathrm{HA} \cdot 3 \mathrm{Ca}$ & 913.3 & 919.9 & 1069.45 & 1128.66 & 0.426 & 0.405 & 1.171 & 1.227 \\
$\mathrm{HA} \cdot 3 \mathrm{Ca} \cdot 9 \mathrm{H}_{2} \mathrm{O}$ & 1070.0 & 1077.8 & 1247.91 & 1320.73 & 0.405 & 0.385 & 1.166 & 1.225 \\
\hline
\end{tabular}

${ }^{a}$ Molecular volume $\left(\AA^{3}\right),{ }^{b}$ Reference calculation carried out with program GEPOL, ${ }^{c}$ Molecular surface area $\left(\AA^{2}\right)$, ${ }^{d}$ Molecular globularity, ${ }^{e}$ Molecular rugosity $\left(\AA^{-1}\right)$.

Figure 9a shows the wire-frame molecular structure of HA. Figure $9 \mathrm{~b}$ reveals the ball-and-stick (B\&S) molecular model of $\mathrm{HA} \cdot 3 \mathrm{Ca} \cdot 9 \mathrm{H}_{2} \mathrm{O}$. The Corey-Pauling-Koltun (CPK) molecular structure of $\mathrm{HA} \cdot 3 \mathrm{Ca} \cdot 9 \mathrm{H}_{2} \mathrm{O}$ (Figure 9c) defines the van der Waals molecular surface area $S$. Notice some small open cavities on CPK surface in agreement with Figure 8 . The water-accessible surface $\mathrm{CPK}^{+}$of $\mathrm{HA} \cdot 3 \mathrm{Ca} \cdot 9 \mathrm{H}_{2} \mathrm{O}$ (Figure 9d) delimits the solvent-accessible surface area AS. Most open cavities on CPK (Figure 9c) close on $\mathrm{CPK}^{+}$surface meaning that they are not accessible to a water molecule (radius $R=1.25 \AA$ ). The $\mathrm{CPK}^{++}$of HA$\cdot 3 \mathrm{Ca} \cdot 9 \mathrm{H}_{2} \mathrm{O}$ (Figure 9e) denotes the surface accessible by a protein side chain $(R=3.50 \AA)$ and is used to calculate the fractal dimension $D$. Again, most open cavities on CPK (Figure 9c) close on $\mathrm{CPK}^{++}$, which are not accessed by a protein side chain. Structures comparison suggests that $\mathrm{HA} \cdot 3 \mathrm{Ca} \cdot 9 \mathrm{H}_{2} \mathrm{O}$ reaction with a molecule or drug begins with water and, even, $\mathrm{Ca}^{2+}$ exchanges in the co-ordination compound. As many drugs are either cationic or zwitterionic, e.g., $65 \%$ of orally available drugs are charged or zwitterionic, $\mathrm{Ca}^{2+}$ exchange is favoured by electrostatics at acidic $\mathrm{pH}$; e.g., drugs metronidazole and minoxidil are ionic pairs.
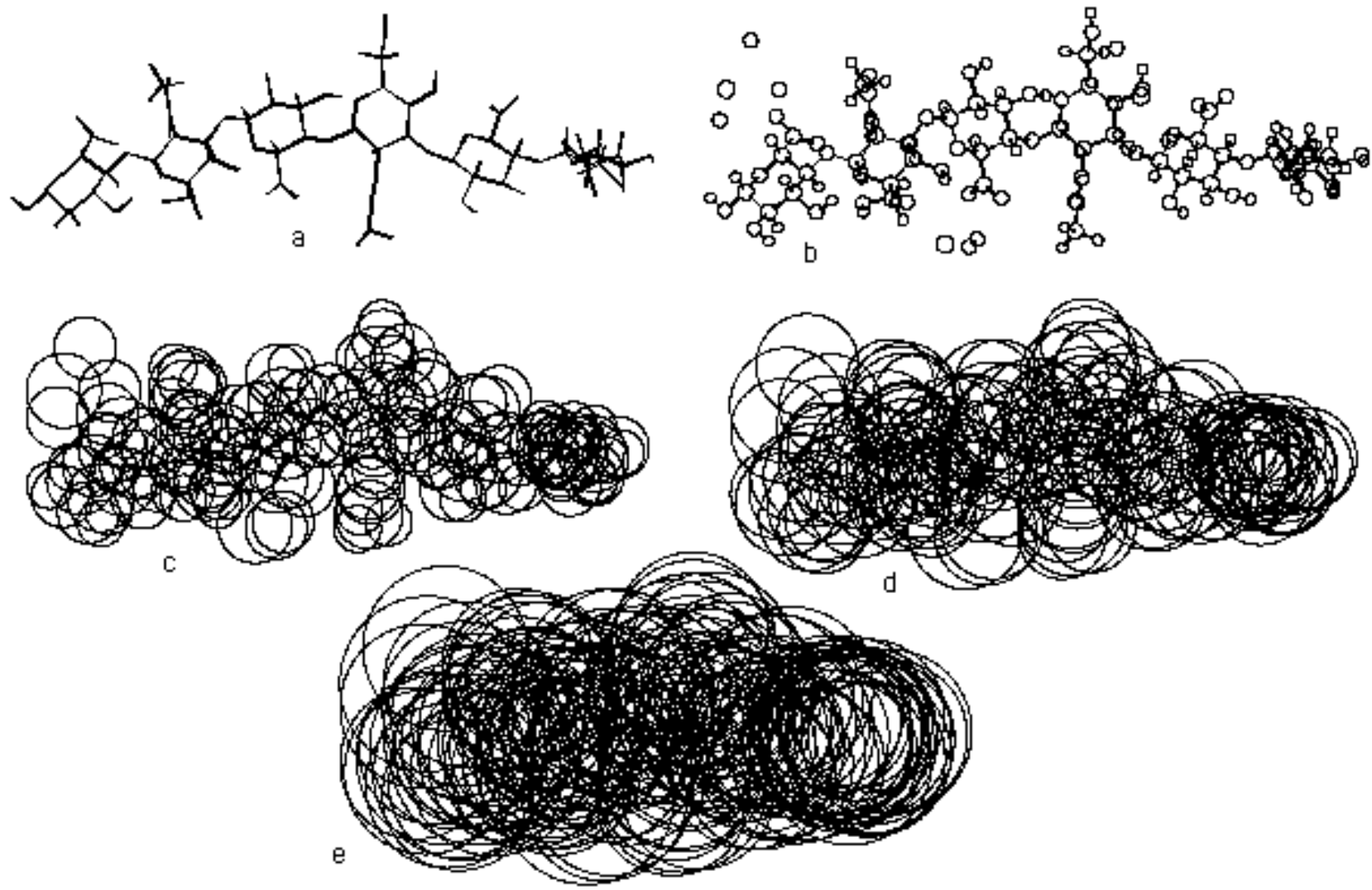

Figure 9. $\mathrm{HA} \cdot 3 \mathrm{Ca} \cdot 9 \mathrm{H}_{2} \mathrm{O}$ molecular structures: (a) wire frame; (b) $\mathrm{B} \& \mathrm{~S} ;$ (c) $\mathrm{CPK}$; (d) $\mathrm{CPK}^{+}$; (e) $\mathrm{CPK}^{++}$. 
Surface $\mathrm{CPK}^{+}$of $\mathrm{HA}$ ( $c f$. Figure 10) shows more open cavities than $\mathrm{HA} \cdot 3 \mathrm{Ca} \cdot 9 \mathrm{H}_{2} \mathrm{O}$ (Figure $9 \mathrm{~d}$ ), which could be accessed by a water molecule.

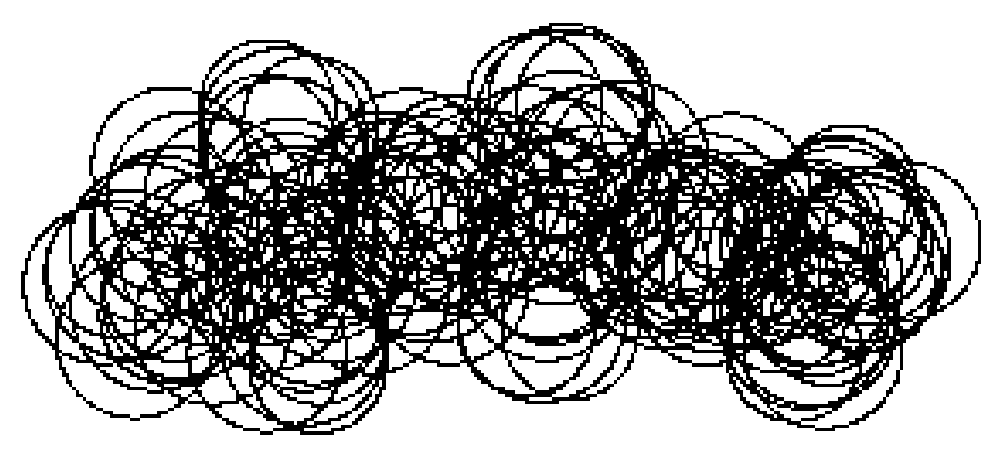

Figure 10. $\mathrm{CPK}^{+}$molecular surface of $\mathrm{HA}$.

Program TOPO allows the atom-to-atom partition analysis of all geometric descriptors. Water solventaccessible surface analysis ( $c f$. Table 5 ) shows that the solvent-accessible surface (AS) area was underestimated by $3 \%$. When going from hexamer $\mathrm{HA}$ to $\mathrm{HA} \cdot 3 \mathrm{Ca}$ and $\mathrm{HA} \cdot 3 \mathrm{Ca} \cdot 9 \mathrm{H}_{2} \mathrm{O}$ the hydrophobic solvent-accessible surface (HBAS) area rose by $42 \%$ and decayed by $26 \%$, respectively. On the other hand, the hydrophilic solvent-accessible surface (HLAS) area dropped by $14 \%$ and increased by $58 \%$. It resulted the most sensitive geometric descriptor for the presence of $\mathrm{Ca}^{2+}$ and, especially, water, in agreement with the highest number of $\mathrm{H}$-bonds in the hydrated co-ordination complex (Table 3). Ongoing from $\mathrm{HA}$ to $\mathrm{HA} \cdot 3 \mathrm{Ca}$ and $\mathrm{HA} \cdot 3 \mathrm{Ca} \cdot 9 \mathrm{H}_{2} \mathrm{O}$, the accessibility enlarged by $9 \%$ and decreased by $8 \%$. The fractal dimension $D$ was underevaluated by $1 \%$. The fractal dimension of $\mathrm{HA}$ turned out to be 1.566 . When going to $\mathrm{HA} \cdot 3 \mathrm{Ca}$ and $\mathrm{HA} \cdot 3 \mathrm{Ca} \cdot 9 \mathrm{H}_{2} \mathrm{O}$, it rose by $2 \%$ and $1 \%$. The low accessibility and relatively low dimension of $\mathrm{HA} \cdot 3 \mathrm{Ca} \cdot 9 \mathrm{H}_{2} \mathrm{O}$ suggest that its reaction requires water or $\mathrm{Ca}^{2+}$ exchange, in agreement with the closed character of $\mathrm{CPK}^{+/++}$surfaces (Figure 9). The fractal dimension averaged for nonburied atoms $D^{\prime}$ increased by $11 \%$ with regard to the molecular dimension. In particular, for HA the external dimension resulted 1.725. Ongoing to $\mathrm{HA} \cdot 3 \mathrm{Ca}$ and $\mathrm{HA} \cdot 3 \mathrm{Ca} \cdot 9 \mathrm{H}_{2} \mathrm{O}$ it augmented by $4 \%$ and $0.3 \%$. When going from $\mathrm{HA}$ to $\mathrm{HA} \cdot 3 \mathrm{Ca}$ and $\mathrm{HA} \cdot 3 \mathrm{Ca} \cdot 9 \mathrm{H}_{2} \mathrm{O}$, the difference nonburied minus molecular dimensions $\left(D^{\prime}-D\right)$ enlarged by $20 \%$ and decayed by $9 \%$. It resulted greatly sensitive to $\mathrm{Ca}^{2+}$ and water incidences.

Table 5. Geometric descriptors and fractal dimensions of the solvent-accessible surface of HA.

\begin{tabular}{cccccccccc}
\hline Molecule & AS $^{\mathrm{a}}$ & AS Ref. $^{b}$ & HBAS $^{\mathrm{c}}$ & HLAS $^{\mathrm{d}}$ & Accessibility $^{\mathrm{e}}$ & $D^{f}$ & $D_{\text {Ref. }}{ }^{\mathrm{b}}$ & $D^{\prime \mathrm{g}}$ & $D^{\prime}-D$ \\
\hline $\mathrm{HA}$ & 1255.03 & 1293.95 & 589.72 & 665.31 & 11.14 & 1.566 & 1.582 & 1.725 & 0.159 \\
$\mathrm{HA} \cdot 3 \mathrm{Ca}$ & 1409.77 & 1453.85 & 834.57 & 575.20 & 12.09 & 1.601 & 1.619 & 1.792 & 0.191 \\
$\mathrm{HA} \cdot 3 \mathrm{Ca} \cdot 9 \mathrm{H}_{2} \mathrm{O}$ & 1530.07 & 1578.40 & 620.88 & 909.19 & 11.15 & 1.625 & 1.644 & 1.798 & 0.173 \\
\hline
\end{tabular}

${ }^{a}$ Water solvent-accessible surface area $\left(\AA^{2}\right),{ }^{b}$ Reference calculation carried out with program GEPOL, ${ }^{c}$ Hydrophobic solventaccessible surface area $\left(\AA^{2}\right),{ }^{d}$ Hydrophilic solvent-accessible surface area $\left(\AA^{2}\right),{ }^{e}$ Accessibility $(\%),{ }^{f}$ Molecular fractal dimension,

${ }^{\mathrm{g}}$ Molecular fractal dimension averaged for nonburied atoms.

Atom-to-atom partition analyses of $\mathrm{HA} \cdot 3 \mathrm{Ca} \cdot 9 \mathrm{H}_{2} \mathrm{O}$ topological indices and fractal dimension, $c f$. Table 6 , show that globularity $\mathrm{G}$ of hydrated co-ordination complex was lower than for $\mathrm{O}$-atoms in water, $\mathrm{Ca}^{2+}$ and averages of O-atoms in $\mathrm{HA}$ in 2.0-2.4. Rugosity $\mathrm{G}^{\prime}$ of $\mathrm{Ca}^{2+}$ was smaller than for hydrate, O-atom averages in $\mathrm{HA}$ in $1.2-1.3 \AA^{-1}$ and $\mathrm{O}$-atoms in water. Hydrate accessibility lay in the range of O-atom averages in $\mathrm{HA}$ (5.9-11.9\%); however, accessibilities of $\mathrm{Ca}^{2+}$ and O-atoms in water (34\%) were much greater. On the other hand, the fractal dimensions of hydrate, $\mathrm{Ca}^{2+}$ and $\mathrm{O}$-atoms in water lay in the range of averages of O-atoms in HA (1.1-3.6). In particular, maximum fractal dimension corresponds to GCU O-atoms for which the utmost reactivity is expected, in agreement with $\mathrm{M}^{2+}$-interchange and $\mathrm{Ag}^{+}$reactions (Figure 4). 
Table 6. Atom-atom partition analyses of $\mathrm{HA} \cdot 3 \mathrm{Ca} \cdot 9 \mathrm{H} 2 \mathrm{O}$ topological indices and fractal dimension.

\begin{tabular}{|c|c|c|c|c|}
\hline Fragment & $G^{\mathrm{a}}$ & $G^{\prime b}$ & Accessibility (\%) & $D^{c}$ \\
\hline Average of $\mathrm{O}$ atoms in $\mathrm{NAG}_{1}$ & 2.415 & 1.177 & 11.94 & 1.104 \\
\hline Average of $\mathrm{O}$ atoms in $\mathrm{GCU}_{1}$ & 2.038 & 1.295 & 8.95 & 3.597 \\
\hline Average of $\mathrm{O}$ atoms in $\mathrm{NAG}_{2}$ & 2.067 & 1.290 & 8.11 & 1.710 \\
\hline Average of $\mathrm{O}$ atoms in $\mathrm{GCU}_{2}$ & 2.069 & 1.270 & 5.93 & 1.358 \\
\hline Average of $\mathrm{O}$ atoms in $\mathrm{NAG}_{3}$ & 2.332 & 1.215 & 9.36 & 2.245 \\
\hline Average of $\mathrm{O}$ atoms in $\mathrm{GCU}_{3}$ & 1.975 & 1.293 & 10.66 & 1.801 \\
\hline Average of $\mathrm{O}$ atoms in NAG & 2.271 & 1.227 & 9.80 & 1.686 \\
\hline Average of $\mathrm{O}$ atoms in $\mathrm{GCU}$ & 2.027 & 1.286 & 8.51 & 2.252 \\
\hline Average of $\mathrm{O}$ atoms in $\mathrm{HA}$ & 2.138 & 1.259 & 9.10 & 1.995 \\
\hline Average of $\mathrm{Ca}^{2+}$ cations & 1.430 & 1.087 & 33.57 & 1.492 \\
\hline Average of $\mathrm{O}$ atoms in $\mathrm{H}_{2} \mathrm{O}$ & 1.258 & 1.733 & 33.54 & 1.700 \\
\hline $\mathrm{HA} \cdot 3 \mathrm{Ca} \cdot 9 \mathrm{H}_{2} \mathrm{O}$ & 0.405 & 1.166 & 11.15 & 1.625 \\
\hline
\end{tabular}

${ }^{a}$ Molecular globularity, ${ }^{b}$ Molecular rugosity $\left(\AA^{-1}\right),{ }^{c}$ Molecular fractal dimension.

\section{Discussion}

Natural polysaccharide $\mathrm{HA}$ gelifies at $\mathrm{pH}<4$. It is characterized by its regenerative properties on different mucous zones, e.g., GI, oral, vaginal, etc. The HA is mainly used in medical and cosmetic applications. Among the many benefits HMW-HA holds in medicine are: (1) the maintenance of tissue space for surgery, (2) protection of cells and tissue and (3) therapeutic effectiveness. Healing efficiency of HA depends critically on MW: the higher the MW, the longer its benefit. The use of HA in cosmetics presents an impact on public health because of the risk of ingredient penetration into the deeper skin layers, which are cleared by systemic circulation (systemic absorption is more likely to occur in injured skin, e.g., sunburnt, atopic, eczematous, psoriatic skin). The problem is important in the case of anticellulite creams as the tissue target is on the dermis. Caffeine, Coleus forskohlii and Nelumbo nucifera extracts are efficacious ingredients of anticellulite cosmetics. In order to develop formulations, it is interesting to enhance their low skin permeabilities (Table 1). However, care should be taken concerning toxicity. Finally, it is proposed that (1) polymer $\mathrm{COOHs}$ react completely with matrix $\mathrm{OHs}$ to give esters, (2) polymer reaction with drugs begins with water or, even, $\mathrm{Ca}^{2+}$ exchange, (3) matrix rheological properties, e.g., $\mathrm{pH}$ dependent gelification, etc., are important and (4) caffeine is a potential lead structure in drug design.

\section{Conclusions}

From the present results and discussion the following conclusions can be drawn:

1. The advantage of program TOPO with respect to GEPOL is that the former allows an atom-to-atom partition analysis of the geometric, topological, fractal indices and their combination: hydrophobic and hydrophilic solvent-accessible surface areas. The latter was detected as the most sensitive geometric descriptor for the presence of $\mathrm{Ca}^{2+}$ and, especially, water, in agreement with the number of $\mathrm{H}$-bonds, which were calculated with TOPO. Ongoing from hyaluronan to $\mathrm{Ca}^{2+}$ co-ordinated to hydrate, accessibility rose by $9 \%$ and decayed by $8 \%$. The relative error with program TOPO is $0.7 \%$ in volume, as well as $5 \%$ in surface area and its derived indices.

2. The fractal dimension was underevaluated by $1 \%$. Ongoing to $\mathrm{Ca}^{2+}$ co-ordinated and hydrate, fractal dimension of hyaluronan (1.566) rose by $2 \%$ and $1 \%$, respectively. The fractal dimensions of nonburied atoms increased by $11 \%$ with regard to molecular fractal indices. Ongoing to $\mathrm{Ca}^{2+}$ co-ordinated to hydrate, fractal dimension of external atoms (1.725) augmented by $4 \%$ and $0.3 \%$. Nonburied minus molecular fractal dimension enlarged by $20 \%$ and decayed by $9 \%$. It was sensitive to $\mathrm{Ca}^{2+}$ and water occurrences. 
3. The hydrate globularity was lower than for O-atoms in water, $\mathrm{Ca}^{2+}$ and $\mathrm{O}$-atom average in hyaluronan. The rugosity of $\mathrm{Ca}^{2+}$ was smaller than for hydrate, $\mathrm{O}$-atoms average in hyaluronan and $\mathrm{O}$ (water). The accessibility of $\mathrm{Ca}^{2+}$ and $\mathrm{O}$ (water) was much greater than for hydrate. The maximum fractal dimension corresponds to D-glucuronic-acid O-atoms for which the utmost reactivity is expected, in agreement with $\mathrm{M}^{2+}$ interchange and $\mathrm{Ag}^{+}$reactions.

4. As cations exchange in hyaluronan co-ordination compound and action requires $\mathrm{Ca}^{2+}$ alteration, the reinforcement of drug cationic/zwitterionic character and acidic $\mathrm{pH}$ increases absorption. Hyaluronan is an articular-cartilage component where it is present as coat around chondrocytes. When aggrecan monomers bind to it in link-protein presence, large, anionic aggregates form, which are responsible for cartilage resilience. Its water interaction, represented by 10-15 H-bonds per disaccharide repeat, indicates binding capacity and importance for cartilage viscoelastic properties. In mucosas, a need for the elimination of pathogens and prophylaxis exists. The hyaluronan rheological behaviour in $\mathrm{pH} 4-7$ did not differ. However, $\mathrm{pH}<4$ generated gels because of hydrophobic interactions and $H$-bonds, which resulted promising for drug administration on mucous membranes and skin.

Further work will analyze polymer reactions with alcohols in the matrix/drugs (eugenol, metronidazole, betamethasone, etc.), matrix rheological properties and caffeine as a potential lead structure in drug design. Caffeine, etc. are efficacious ingredients of anticellulite cosmetics. However, care should be taken concerning toxicity, especially for injured skin. Work is in progress on the prediction of chromatographic retention times and molecular classification of (1) tea compounds and (2) methylxanthines (caffeine and its metabolites) and nicotine-metabolite cotinine in human plasma.

Acknowledgements: F. T. thanks support from the Spanish Ministerio de Economía y Competitividad (Project No. BFU2013-41648-P) and EU ERDF.

\section{References}

[1] E.A. Balazs, Ed., The Chemistry and Molecular Biology of the Intercellular Matrix, Academic, New York, NY, 1970

[2] B. Alberts, A. Johnson, J. Lewis, M. Raff, K. Roberts, P. Walter, Molecular Biology of the Cell, Garland, New York, NY, 2002

[3] T.C. Laurent, J.R.E. Fraser, FASEB J. 6 (1992) 2397-2404

[4] K.L. Goa, P. Benfield, Drugs 47 (1994) 536-566

[5] E. Zimmerman, B. Geiger, L. Addadi, Biophys. J. 82 (2002) 1848-1857

[6] M. Moulabbi, H. Broch, L. Rober, D. Vasilescu, J. Mol. Struct. (THEOCHEM) 395-396 (1997) 477-508

[7] P. Sipos, M. Veber, K. Burger, J. Illes, G. Machula, Acta Chim. Hung. Models Chem. 129 (1992) 671683

[8] E.R. Morris, D.A. Rees, E.J. Welsh, J. Mol. Biol. 138 (1980) 383-400

[9] N. Figueroa, B. Nagy, B. Chakrabarti, Biochem. Biophys. Res. Commun. 74 (1977) 460-465

[10] H. Sterk, M. Braun, O. Schmut, H. Feichtinger, Carbohydr. Res. 145 (1985) 1-11

[11] L. Lapcik, C. Dammer, M. Valko, Colloid Polym. Sci. 201 (1992) 1049-1052

[12] J.K. Sheehan, E.D. Atkins, Int. J. Biol. Macromol. 5 (1983) 215-221

[13] E.D. Atkins, J.K. Sheehan, C.F. Phelps, Biochem. J. 128 (1972) 1255-1263

[14] A.K. Mitra, S. Raghunathan, J.K. Sheehan, S. Arnott, J. Mol. Biol. 169 (1983) 829-859

[15] W.T. Winter, S. Arnott, J. Mol. Biol. 117 (1977) 761-784 
[16] E. Tratar Pirc, I. Arcon, P. Bukovec, A. Kodre, Carbohydr. Res. 324 (2000) 275-282

[17] E. Tratar Pirc, I. Arcon, A. Kodre, P. Bukovec, Carbohydr. Res. 339 (2004) 2549-2554

[18] R. Eklund, G. Widmalm, Carbohydr. Res. 338 (2003) 393-398

[19] A. Warshel, M. Levitt, J. Mol. Biol. 103 (1976) 227-249

[20] B.R. Brooks, R.E. Bruccoleri, B.D. Olafson, D.J. States, S. Swaminatham, M. Karplus, J. Comput. Chem. 4 (1983) 187-217

[21] A.D. Becke, Phys. Rev. A 38 (1988) 3098-3100

[22] C.T. Lee, W.T. Yang, G. Parr, Phys. Rev. B 37 (1988) 785-789

[23] A.D. MacKerell Jr., D. Bashford, M. Bellott, R.L. Dunbrack Jr., J.D. Evanseck, M.J. Field, S. Fischer, J. Gao, H. Guo, S. Ha, D. Joseph-McCarthy, L. Kuchnir, K. Kuczera, F.T.K. Lau, C. Mattos, S. Michnick, T. Ngo, D.T. Nguyen, B. Prodhom, W.E. Reiher III, B. Roux, M. Schlenkrich, J.C. Smith, R. Stote, J. Straub, M. Watanabe, J. Wiórkiewicz-Kuczera, D. Yin, M. Karplus, J. Phys. Chem. B 102 (1998) 35863616

[24] E. Tratar Pirc, J. Zidar, P. Bukovec, M. Hodoscek, Carbohydr. Res. 340 (2005) 2064-2069

[25] L. Masgrau, A. Roujeinikova, L.O. Johannissen, P. Hothi, J. Basran, K.E. Ranaghan, A.J. Mulholland, M.J. Sutcliffe, N.S. Scrutton, D. Leys, Science 312 (2006) 237-241

[26] J. Zidar, E. Tratar Pirc, M. Hodoscek, P. Bukonec, J. Chem. Model. 48 (2008) 283-287

[27] Y. Zhao, D. Truhlar, Theor. Chem. Acc. 120 (2008) 215-241

[28] B.R. Brooks, C.L. Brooks III, A.D. Mackerell Jr., L. Nilsson, R.J. Petrella, B. Roux, Y. Won, G. Archontis, C. Bartels, S. Boresch, A. Caflisch, L. Caves, Q. Cui, A.R. Dinner, M. Feig, M. Fischer, J. Gao, M. Hodoscek, W. Im, K. Kuczera, T. Lazaridis, J. Ma, V. Ovchinnikov, E. Paci, R.W. Pastor, C.B. Post, J.Z. $\mathrm{Pu}$, M. Schaefer, B. Tidor, R.M. Venable, H.L. Woodcock, X. Wu, W. Yang, D.M. York, M. Karplus, J. Comput. Chem. 30 (2009) 1545-1614

[29] T.E. Hofstetter, C. Howder, G. Berden, J. Oomens, P.B. Armentrout, J. Phys. Chem. B 115 (2011) 12648-12661

[30] M. Remko, D. Fitz, R. Broer, B.M. Rode, J. Mol. Model. 17 (2011) 3117-3128

[31] M.H. Khodabandeh, R. Hamid, K. Zare, M. Zahedi, Int. J. Mass Spectrom. 313 (2012) 47-57

[32] P.E. Siegbahn, J. Biol. Inorg. Chem. 11 (2006) 695-701

[33] Y. Minenkov, Å. Singstad, G. Occhipinti, V.R. Jensen, Dalton Trans. 41 (2012) 5526-5541

[34] E. Tratar Pirc, J. Zidar, P. Bukovec, Int. J. Mol. Sci. 13 (2012) 12036-12045

[35] D. Heinegård, Å. Oldberg, FASEB J. 3 (1989) 2042-2051

[36] G.S. Asane, S.A. Nirmal, K.B. Rasal, A.A. Naik, M.S. Mahadik, Y.M. Rao, Drug Dev. Ind. Pharm. 34 (2008) 1246-1266

[37] N.A. Peppas, P.A. Buri, J. Control Release 2 (1985) 257-275

[38] J.M. Gu, J.R. Robinson, S.H. Leung, Crit. Rev. Ther. Drug Carrier Syst. 5 (1988) 21-67

[39] J. Woodley, Clin. Pharmacokinet. 40 (2001) 77-84

[40] J.D. Smart, Adv. Drug Deliv. Rev. 57 (2005) 1556-1568

[41] F. Torrens, Molecules 8 (2003) 169-185

[42] F. Torrens, Molecules 9 (2004) 1222-1235

[43] F. Torrens, Leb. Sci. J. 5(1) (2004) 61-70

[44] F. Torrens, G. Castellano, J. Liq. Chromatogr. Relat. Technol. 31 (2008) 2337-2347

[45] F. Torrens, G. Castellano, A. Campos, C. Abad, J. Mol. Struct. 924-926 (2009) 274-284

[46] F. Torrens, G. Castellano, Anal. Chim. Acta 654 (2009) 2-10

[47] F. Torrens, G. Castellano, J. Life Sci. 5 (2011) 167-181

[48] F. Torrens, G. Castellano, Asia Pacific J. Life Sci. 5 (2013) 89-121

[49] F. Torrens, G. Castellano, J. Mater. Sci. Eng. B 4(2) (2014) 55-63 
[50] F. Torrens, E. Ortí, J. Sánchez-Marín, J. Chim. Phys. Phys.-Chim. Biol. 88 (1991) 2435-2441

[51] A.Y. Meyer. J. Chem. Soc., Perkin Trans. 21985 (1985) 1161-1169

[52] A.Y. Meyer, J. Comput. Chem. 9 (1988) 18-24

[53] B. Lee, F.M. Richards, J. Mol. Biol. 55 (1971) 379-400

[54] R.B. Hermann, J. Phys. Chem. 76 (1972) 2754-2759

[55] A. Bondi, J. Phys. Chem. 68 (1964) 441-451

[56] S.J. Wodak, J. Janin, Proc. Natl. Acad. Sci. U. S. A. 77 (1980) 1736-1740

[57] M. Lewis, D.C. Rees, Science 230 (1985) 1163-1165

[58] F. Torrens, J. Sánchez-Marín, I. Nebot-Gil, J. Comput. Chem. 22 (2001) 477-487

[59] F. Torrens, M. Rubio, J. Sánchez-Marín, Comput. Phys. Commun. 115 (1998) 87-89

[60] J.L. Pascual-Ahuir, E. Silla, J. Tomasi, R. Bonaccorsi, J. Comput. Chem. 8 (1987) 778-787

[61] B. Terryn, J. Barriol, J. Chim. Phys. Phys.-Chim. Biol. 78 (1981) 207-212

[62] X. Xu, A.K. Jha, D.A. Harrington, M.C. Farach-Carson, X. Jia, Soft Matter 8 (2012) 3280-3294

[63] S.A.A. Al-Abdulla, N.A.H. Al-Assady, S.G. Syyah, J. Thi-Qar Sci. 3 (2012) 129-140

[64] R.C. Polexe, T. Delair, Molecules 18 (2013) 8563-8578

[65] A.M. Abdel-Mohsen, R. Hrdina, L. Burget, G. Krylova, R.M. Abdel-Rahman, A. Krejcova, M. Steinhart, L. Benes, Carbohydr. Polym. 89 (2012) 411-422

[66] D. Chudobova, L. Nejdl, J. Gamulec, O. Krystofova, M.A. Merlos Rodrigo, J. Kynicky, B. RuttkayNedecky, P. Kopel, P. Babula, V. Adam, R. Kizek, Int. J. Mol. Sci. 14 (2013) 13592-13614

[67] R.O. Potts, R.H. Guy, Pharm. Res. 9 (1992) 663-669

[68] C.D. Freeman, N.E. Klutman, K.C. Lamp, Drugs 54 (1997) 679-708

[69] S. Löfmark, C. Edlund, C.E. Nord, Clin. Infect. Dis. 50 (2010) S16-S23

[70] M.J.S. Dewar, E.G. Zoebisch, E.F. Healy, J.J.P. Stewart, J. Am. Chem. Soc. 107 (1985) 3902-3909

C2014 by the authors; licensee IAPC, Zagreb, Croatia. This article is an open-access article distributed under the terms and conditions of the Creative Commons Attribution license (http://creativecommons.org/licenses/by/3.0/) (cc)) EY 